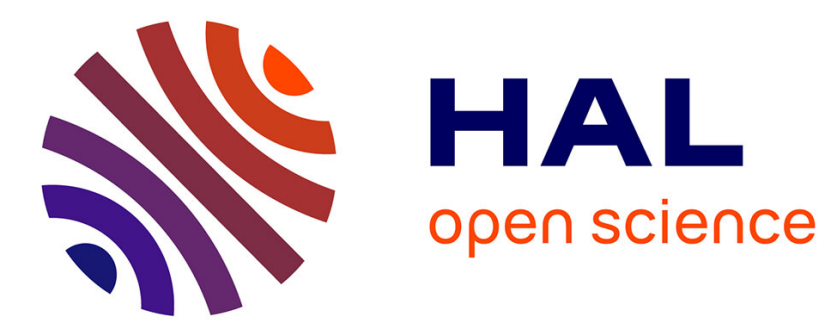

\title{
Contribution à l'histoire de la forêt sur le plateau de Millevaches
}

\author{
Marius Vazeilles
}

\section{To cite this version:}

Marius Vazeilles. Contribution à l'histoire de la forêt sur le plateau de Millevaches. Revue forestière française, 1955, 3, pp.217-220. 10.4267/2042/27077 . hal-03383969

\section{HAL Id: hal-03383969 \\ https://hal.science/hal-03383969}

Submitted on 18 Oct 2021

HAL is a multi-disciplinary open access archive for the deposit and dissemination of scientific research documents, whether they are published or not. The documents may come from teaching and research institutions in France or abroad, or from public or private research centers.
L'archive ouverte pluridisciplinaire HAL, est destinée au dépôt et à la diffusion de documents scientifiques de niveau recherche, publiés ou non, émanant des établissements d'enseignement et de recherche français ou étrangers, des laboratoires publics ou privés. 


\title{
CONTRIBUTION A L'HISTOIRE DE LA FORET SUR LE PLATEAU DE MILLEVACHES
}

\author{
Le battoir de laveuse trouvé à La Feuillade \\ (commune de Meymac)
}

Une curieuse trouvaille, celle d'un battoir de laveuse, vient s'ajouter à d'autres pour aider à l'édification de l'histoire de la Forêt sur le plateau de Millevaches.

La Luzège, affluent rive droite de la Dordogne, prend la plupart de ses sources dans le cirque de Lontrade qui occupe une surface d'environ 2000 hectares de la commune de Meymac (Corrèze). La rivière, à $7 \mathrm{~km}$ de ses naissances, vient déboucher au nord du cheflieu par un étroit ravin entre la croupe ide La Feuillade et celle du Jassoneix.

Le glacier qui a creusé cette gorge a disparu peu à peu, il y a Io à I 5000 ans. Avant de s'étaler dans la large vallée qui caractérise le site de Meymac, il a laissé, sur les versants abrupts de sa sortie resserrée, des moraines latérales très nettes.

Il y a quelque vingt ans, la Caisse de compensation de la Région Parisienne a aménagé une colonie de vacances à l'emplacement de l'ancienne ferme de La Feuillade sur la rive gauche, au débouché de la partie étroite de la vallée. On a creusé récemment près du bas de la pente, à une vingtaine de mètres du thalweg, en avant du grand bâtiment, une fosse septique qui a nécessité un creusement de $3,50 \mathrm{~m}$ de profondeur, soit à peu près jusqu'au niveau de l'étiage actuel de la Luzège. Celle-ci coule sur un comblement ancien et épais fait surtout de tourbe ou de terre tourbeuse, ainsi que cela a été reconnu un peu en amont lors de l'aménagement d'une piscine.

Le creusement de la fosse septique a atteint, à un niveau supérieur au comblement ancien. les blocs du bas de la moraine latérale.

Au-dessus de leur amas recouvert d'argile s'étagent plusieurs couches de tourbe ou de tourbe terreuse alternant avec des couches de sable, le tout dans l'ordre suivant, à partir du bas de la fosse: 


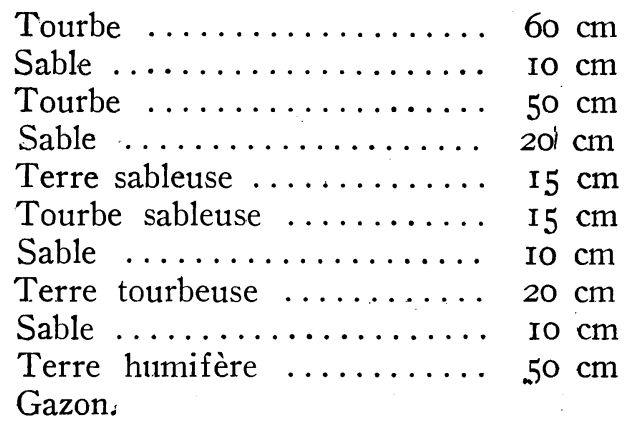

La parcelle est portée pré au cadastre qui, à Meymac, est fait depuis I 30 ans.

C'est sur l'argile cimentant les blocs et sous la première couche de tourbe, soit à 2,60 $\mathrm{m}$ au-dessous de la surface gazonnée que les ouvriers ont trouvé un battoir de laveuse en bois de chêne assez bien conservé, surtout sur un côté, le côté le plus plat.

Les dimensions de cet objet sont les suivantes: longueur totale, $3 \mathrm{I} \mathrm{cm}$, dont I 5 pour le manche; largeur de la pelle assez maladroitement carrée, $15 \mathrm{~cm}$; épaisseur variant de 2 à $3 \mathrm{~cm}$.

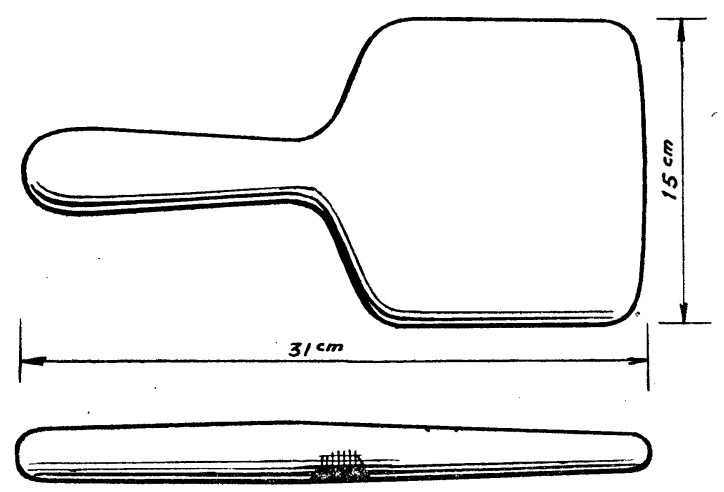

A quelle époque cet ustensile a-t-il été abandonné où il vient d'être trouvé?

Qu'il ait appartenu à une laveuse de la ferme d'autrefois de La Feuillade ou bien qu'il soit descendu avec une crue de la Luzège d'un des hameaux du cirque Lontrade-Lavialle, il est certain que nous nous trouvons en face d'une relique d'un âge ancien. Il a fallu, en effet, des siècles, pour que s'accumulent, peu à peu, sur elle, près de 3 mètres de matériaux, surtout si l'on convient que la tourbe 
se forme lentement et que les couches profondes se sont fortement tassées.

Je ne puis m'empêcher de penser à un battoir de l'époque romaine en IGaule ou du début du haut moyen âge. Une villa du II ${ }^{e}$ siècle existait à Lavialle et j'ai trouvé des vestiges des temps mérovingiens à Lontrade.

Comment expliquer convenablement un dépôt épais de plusieurs mètres sur un objet en somme historique à un endroit où depuis très longtemps la surface est occupée par une bonne prairie naturelle sur sol granitique humifère?

D'autre part, à quoi peut servir l'étude de ce dépôt avec ses couches superposées?

Essayons une analyse.

La Luzège a eu à plusieurs époques un cours régulier. Ruisseau tranquille durant une période assez longue, elle étalait ses eaux à la sortie de la gorge de la Feuillade et provoquait alors la formation de la tourbe.

C'était aux époques où le sol possédait sur les pentes sa couverture forestière plus ou moins complète, ou bien celles où le pâturage réduit ne dénudait pas le sol et où la culture par labour était peu développée.

Mais il est arrivé souvent que la petite rivière a pris un régime torrentiel. C'est à la suite de déforestation poussée trop loin et suivie de pâturage sans discernement arrivant à une sensible dénudation des pentes. C'est aussi à la suite d'une extension de la culture sur de grandes surfaces. C'est enfin et surtout à mon avis lorsque la pratique de l'écobuage a feu couvert pour champs temporaires, s'est étendue jusqu'au sommet des croupes.

Le ruissellement intense sur les surfaces dénudées ou cultivées a alors, sur les pentes, provoqué le ravinement et l'entraînement de masses de terre dont les éléments sableux se sont 'arrêtés à la sortie du ravin.

En conséquence, la présence sur les versants de la forêt ou de pâturages non épuisés ou entrecoupés de champs à un taux de surface réduit et convenable pour la montagne, se trouve aujourd'hui signalée par une couche de tourbe ou par un sol au moins tourbeux.

Les périodes de défrichement et de grande culture sont marquées par des couches de sable ou au moins de terre sableuse.

A noter ici que lors du creusement des fouilles pour la conduite d'eau du hameau voisin de Lavaur, au pied du versant du Jassonneix, j'ai retrouvé la même alternance (terre humifère et sable pur) dans les champs en plaine au bas de la pente.

D'autre part, les analyses polliniques que M. le Professeur LEMÉE de la Faculté de.Strasbourg a bien voulu me faire des couches de tourbe d'une tourbière voisine permettent des remarques 
intéressantes. Les couches étudiées sont celles à partir de la poterie gauloise préromaine jusqu'à la surface gazonnée. Ces analyses ont donné des résultats intéressants non seulement sur la composition de la flore forestière du plateau, mais sur l'existence et l'importance quantitative des plañtes cultivées.

Dès son début, la période gallo-romaine a été une période de culture assez développée (I).

Mais après les Invasions Barbares et par suite de la décadence romaine. il faudra attendre jusqu'à la Renaissance pour avoir à nouveau un maximum de pollen de céréales et de plantes rudérales.

Malheureusement, dès le Xvi siècle, à la culture sage par champs permanents entrecoupés de prairies, de pâtures et de bois, succéderont, avec des hauts et des bas, l'extension sans discernement du pâturage ovin et la pratique de l'écobuage à feu couvert poussé très loin.

On comprend que ces données nouvelles relatives à la situation d11 battoir sous des couches diverses et celles fournies par l'analyse pollinique de la tourbière voisine de "Rié-Grand 》 puissent contribuer à l'histoire de la forêt sur le Plateau de Millevaches depuis environ le début de notre ère.

Plus en contre-bas, c'est-à-dire plus près de la ligne du thalweg, la tourbe, souvent sableuse, se retrouve sous le lit actuel de la $\mathrm{Lu}$ zège, avant d'atteindre les blocs et galets de la moraine frontale en retrait.

Cette couche varie d'épaisseur suivant les endroits et, par sa composition et ses alternances, elle raconte la plus vieille histoire de notre forêt, celle qui s'est déroulée entre la fin de la toundra et la période de culture des derniers millénaires avant J.-C.

Bien entendu, il faudrait pouvoir mettre une date plus précise sur chacune des trois importantes couches de tourbe qui se sont formées après le dépôt dı battoir. Mais n'est-ce pas émotionnant de trouver aussi profondément placé et conservé l'humble outil d'une laveuse gauloise.

Marius Vazeilles.

Ancien Garde Général du Plateau de Millevaches.

(I) Dans la commune de Meymac qui s'étend sur 8715 hectares, dont la moitié sur le plateau au-dessus de 800 mètres, et le reste au-dessous de 700 , altitude du Bourg, je connais I8 centres agricoles de la grande époque galloromaine. tous marqués par les tuiles, briques et tessons caractéristiques.

\author{
Au Salon de la Machine Agricole \\ voyez le Stand du Centre Technique du Bois
}

